Nevşehir Bilim ve Teknoloji Dergisi TARGíD Özel Sayı 189-198 2016

DOI: 10.17100/nevbiltek.210987

URL: http://dx.doi.org/10.17100/nevbiltek.210987

\title{
Orta Karadeniz Bölgesi Seralarındaki Kök-Ur Nematodlarının Yayılış ve Bulaşıklık Oranı
}

\author{
Gökhan Aydınlı ${ }^{1, *}$, Sevilhan Mennan ${ }^{2}$ \\ ${ }^{1}$ Bozok Üniversitesi, Tarım ve Doğa Bilimleri Fakültesi, Bitki Koruma Bölümü, Yozgat \\ ${ }^{2}$ Ondokuz Mayıs Üniversitesi, Ziraat Fakültesi, Bitki Koruma Bölümü, Samsun
}

Öz

Kök-ur nematodları (Meloidogyne spp.) tüm dünyada sebze yetiştirilen seralarda önemli verim kayıplarına neden olmaktadır. Türkiye’nin Orta Karadeniz Bölgesi’ndeki sera alanlarında kök-ur nematodlarının yayılışı ve bulaşıklı seviyesini belirlemek amaciyla Samsun, Amasya, Tokat ve Sinop illerinde 2011 y1lında, Ordu ve Çorum illerinde ise 2012 y1lında surveyler gerçekleştirilmiştir. Survey çalışmaları sırasında incelenen 414 seradan \%39,61'nin (164 sera) kök-ur nematodu ile bulaşık olduğu tespit edilmiştir. Kök-ur nematodları ile bulaşıklık oranı bakımından Samsun $(\% 46,67)$ en yüksek bulaşıklık oranına sahip olurken, bunu sırasıyla Ordu (\%43,33), Sinop (\%41,38), Tokat $(\% 30,23)$, Çorum $(\% 30)$ ve Amasya $(\% 25,81)$ illeri takip etmektedir. Seralarda yetiştirilen sebze türüne göre, hıyar seralarının \%48,16'sı, biber seralarının \%29,17'si ve domates seralarının \%25'inin kök-ur nematodları ile bulaşık olduğu tespit edilmiştir. Bulaşık seralarda en yaygın görülen ur skalası değerleri 7 (\%10,87), 8 $(\% 8,70)$ ve $9(\% 7,73)$ 'dur. Çalışma sonucunda, Orta Karadeniz Bölgesi’nin sahil kesimlerinde yer alan illerdeki seraların kök-ur nematodu ile bulaşılık oranlarının, iç kesimde yer alanlara göre daha yüksek olduğu belirlenmiştir.

Anahtar Kelimeler: Orta Karadeniz Bölgesi, kök-ur nematodu, sera, yayılış, bulaşıklık oranı.

\section{Distribution and Infestation Rate of Root-Knot Nematodes in Greenhouses of the Middle Black Sea Region}

\begin{abstract}
Root-knot nematodes (Meloidogyne spp.) are causing serious yield losses in greenhouse-grown vegetables crops worldwide. Surveys of greenhouse in The Middle Black Sea Region of Turkey were conducted in Samsun, Amasya, Tokat ve Sinop provinces in 2011 and Ordu and Çorum provinces in 2012 to determine the distribution and infestation rates of root-knot nematodes. It was found that 39,61\% of 414 greenhouse were infected with root-knot nematodes. The infestation rate of root-knot nematodes was highest in Samsun (46,67\%) province, followed by Ordu (43,33\%), Sinop (41,38\%), Tokat (30,23\%), Çorum (30\%) and Amasya (25,81\%). Of all the associated species of vegetables growing greenhouse, $48,16 \%$ of cucumber greenhouses, $29,17 \%$ of pepper greenhouses and $25 \%$ of tomato greenhouses were infested with root-knot nematodes. The most common galling index from infested greenhouses was 7 (10,87\%), 8 (8,70\%) and 9 (7,73\%). The results of study showed that infestation rates of root-knot nematode in greenhouses from coastal provinces of the Middle Black Sea Region were higher than that of the inland provinces.
\end{abstract}

Keywords: Middle Black Sea Region, root-knot nematode, greenhouse, distrubiton, infestation rate

*e-mail: gokhan.aydinli@bozok.edu.tr 
Aydınlı G., Mennan S.

\section{Giriș}

Hızla artan dünya nüfusunun gıda gereksiniminin karşılanabilmesi için, birim alandan daha fazla verim alınması gerekmektedir. Örtüaltı yetiştiriciliği, birim alandan yüksek verim alınmasına olanak sağlayacak en önemli tarımsal faaliyetlerden olup, özellikle yıl içinde düzenli iş gücü kullanımı nedeniyle de ülkemizde gittikçe gelişmektedir [1]. Örtüaltı yetiştiriciliği cam sera, plastik sera, yüksek tünel ve alçak tünellerde yapılmakta olup, alçak tünel dışındaki diğer örtüaltı yetiştiricilik sistemleri ülkemizde "sera alanı" olarak ifade edilmektedir [2]. Toplam örtüaltı alanımız 2012 yılı itibarı ile 617.760 da ulaşmış olup, bu alanın \%26'sını alçak tünel, \%74'ünü ise sera alanları oluşturmaktadır [3]. Ülkemizdeki toplam örtüaltı alanlarımızın \%82’si Akdeniz Bölgesi’nde, bunu Ege ve Karadeniz Bölgeleri izlemektedir. Karadeniz Bölgesi’nde Samsun ili örtüaltı yetiştiriciliğinin en yoğun yapıldığı il olup, bu alanların büyük bir bölümünü alçak tüneller (\%69) oluşturmaktadır. Sera olarak ifade edilen toplam alan ise 2012 yılı itibarı ile 6.615 da'dır [3]. Samsun iline komşu olan diğer iller içerisinde, en yüksek sera alanları sırasıyla Amasya, Tokat, Sinop, Ordu ve Çorum illerindedir. Orta Karadeniz Bölgesi’nin iç kesiminde yer alan Amasya ilinde, son 10 yılda seracılık yaklaşık dört kat artmıştır [3].

Üretimin yoğun olarak yapıldığı seralar, sadece yetiştirilen bitkiler için değil, kök-ur nematodları (Meloidogyne spp.) gibi zararlılar için de en uygun koşullara sahiptir. Bitki köklerinde neden oldukları “ur” şeklindeki yapılar, topraktan su ve besin maddesi alımını olumsuz yönde etkilediğinden, bitkilerde gelişmenin yavaşlamasına, durmasına ve populasyonun yüksek olduğu durumlarda; bitkilerin tamamen kurumasına neden olur [4]. Toprak gibi son derece kompleks bir ekosistemi habitat olarak seçtiklerinden, tek başına kök-ur nematodlarından kaynaklanan zararın hesaplanması güçtür. Çoğu kültür bitkisinde kökur nematodlarına tolerans sınırı, $1 \mathrm{~cm}^{3}$ toprakta 1 adet nematod yumurtasından daha azdır [5]. Bitkide oluşan zarar oranı, nematod yoğunluğu ve bitkinin çeşidine bağlı olarak değişmekte olup, sebzelerde sadece kök-ur nematodlarının neden olduğu ürün kaybının ortalama \%10 olduğu [6], bazı kaynaklarda ise bu oranın \%50-80 arasında değiştiği bildirilmektedir [7 ve 8]. Bu kayıpların domateslerde \%24-38, patlıcanlarda \%17-20 ve kavunda \%18-33 oranlarında olduğu belirtilmiştir [9].

Ülkemizde kök-ur nematodu, ilk kez Samsun ilinde 1934 yılında Nihat İyriboz tarafindan tespit edilmiştir [10]. Türkiye'deki zararlı nematod faunası üzerine yapılan ilk incelemelerde, aralarında Amasya, Samsun ve Tokat'ında bulunduğu 30 ilin 77 ilçesindeki birçok köyün, kök-ur nematodları ile bulaşık olduğu da belirtilmiştir [11]. Sinop’tan Gürcistan sınırına kadar sahil kesiminde 1962 ve $1964-$ 1965 yıllarında Yüksel [12] tarafından yapılan tetkik gezisinde, bölgenin bu zararlı ile bulaşık olduğu bildirilmiştir. Karadeniz Bölgesi’nde 1961-1968 yılları arasında yapılan çalışmada ise özellikle sahil boyunca kumsal toprakların, Amasya’nın Yeşilırmak'la sulanan sebze alanlarının, Turhal, Niksar ve Trabzon'un tütün ekili alanlarının, farklı yoğunluklarda kök-ur nematodları ile bulaşık olduğu saptanmıştır [13]. Bafra ve Çarşamba Ovaları'ndaki yazlık sebze alanlarında gerçekleştirilen survey çalışmalarında ise bulaşıklık oranının sırasıyla \%22 ve \%27 olduğu saptanmıştır [14]. Aynı bölgede sera alanlarında yürütülen bir çalışmada ise incelenen 150 seradan 80 (\%53)'i bulaşık olarak tespit edilmiş ve en fazla bulaşıklık oranının hıyar (\%58) ve domates (\%26) bitkisinde olduğu bildirilmiştir [15]. Tokat ilinde sera ve açık alanda yetiştirilen sebzelerde yapılan survey çalışmasında ise sadece Erbaa $(\% 34,5)$ ve Niksar (\%5,5) ilçelerinde kök-ur nematodunun bulaşıklığına rastlandığı bildirilmiştir [16]. 
Bu çalışmanın amacı, Orta Karadeniz Bölgesi'nde Samsun başta olmak üzere Amasya, Tokat, Sinop, Ordu ve Çorum illerinde seracılı̆̆ın gelişmesine engel olabilme potansiyelindeki kök-ur nematodlarının yayılışı ve bulaşıklık seviyesini belirlemektir.

\section{Materyal ve Metot}

Orta Karadeniz Bölgesi seralarındaki kök-ur nematodlarının yayılışını ve bulaşıklık seviyesini belirlemek amacıyla, 2011 yılı Temmuz ayında Samsun, Amasya, Tokat, Sinop illerinde, 2012 y1lı Eylül ayında ise Ordu ve Çorum illerinde arazi çalışmaları yapılmıştır. İllerdeki sera üretim alanları dikkate alınarak örnekleme sayıları belirlenmiş ve survey yapılmıştır (Tablo 1). Arazi çalışmalarında özellikle seracılığın yoğun yapıldığı alanlar hedef alınmıştır. Arazi çalışmasının yapıldığı bazı lokasyonlarda çok sayıda sera bir arada bulunduğundan, tesadüfi olarak seçilen seralar incelemeye alınmıştır.

Tablo 1. Orta Karadeniz Bölgesi’nde arazi çalışmasının yapıldığı yıllarda illere göre sera ve yazlık bitki ekiliş alanları*

\begin{tabular}{ccccccc}
\hline IIller & $\begin{array}{c}\text { Sera Üretim } \\
\text { Alanı (da) }\end{array}$ & Hıyar & Domates & Biber & Fasulye & Patlıcan \\
\hline Samsun & 6768 & 2444 & 1939 & 1853 & 220 & 108 \\
Amasya & 1245 & 661 & 563 & 1 & - & - \\
Tokat & 532 & 236 & 86 & 49 & 2 & 13 \\
Sinop & 309 & 107 & 67 & 21 & 24 & 30 \\
Çorum & 216 & 156 & 45 & 10 & 3 & - \\
Ordu & 206 & 119 & 61 & 2 & 5 & -
\end{tabular}

* Samsun, Amasya, Tokat ve Sinop için 2011, Çorum ve Ordu için ise 2012 yılı verileri kullanılmıştır. Türkiye İstatistik Kurumu (http:/tuikapp.tuik.gov.tr/bitkiselapp/bitkisel.zul).

Kök-ur nematodlarının dağılışını ve bulaşıklık seviyesini belirlemek amacıyla yapılan arazi çalışmasında, mümkün olduğunca fazla sayıda ve değişik lokasyondaki seralar incelenmeye çalışılmıştır. Seralar incelenirken öncelikli olarak solgunluk, gelişme geriliăi gibi kök-ur nematodu belirtisi gösteren bitkiler hedef alınmıştır. Bitki gelişiminin sağlam görüldüğü seralarda ise zig-zag şeklinde hareket edilerek, serayı temsil edecek şekilde sera büyüklüğüne bağlı olarak 5-10 bitki kökü kontrol edilmiştir. Bitkilerin kök örnekleri, 0-10 skalasına (Şekil 1) göre değerlendirilerek, seraların bulaşıklık seviyesi ortaya konulmaya çalışılmıştır [17]. Köklerinde ur oluşumuna rastlanmayan kültür bitkilerinin bulunduğu seralarda, mevcut olan bazı yabancı otlar da kontrol edilerek seranın bulaşıklık durumuna karar verilmiş̧ir. Özellikle dayanıklı domates çeşitlerin yetiştirildiği bazı seralarda, köpek üzümü (Solanum nigrum L.) gibi kök-ur nematodunun konukçusu olan yabancı otlar kontrol edilmiştir.

Çalışmanın yürütüldüğü lokasyonlardaki seraların ve bitkilerin kök-ur nematodu ile bulaşıklığı yüzde (\%) üzerinden değerlendirilmiştir. Ayrıca survey yapılan illerde seraların ur skalası değerlerine göre bulaşıklık seviyesi belirlenmiştir.

\section{Bulgular}

Samsun, Amasya, Tokat ve Sinop illerinde 2011 yılı Temmuz ayında, Ordu ve Çorum illerinde ise 2012 yılı Eylül ayında olmak üzere, toplam 414 serada yapılan survey çalışması ile sera alanlarındaki kök-ur nematodlarının yayılış ve bulaşıklık oranları belirlenmiştir. Bölgede incelenen seraların 
\%39,61'inin (164 sera) kök-ur nematodu ile bulaşık olduğu tespit edilmiştir (Tablo 2). Bulaşıklık oranı bakımından Samsun ili \%46,67 ile ilk sırada yer alırken, bunu sırasıyla \%43,33 ile Ordu ve \%41,38 ile Sinop izlemektedir. Orta Karadeniz Bölgesi’nin iç kesimlerinde yer alan Tokat (\%30,23), Çorum (\%30) ve Amasya $(\% 25,81)$ illerinde ise kök-ur nematodunun bulaşık oranı, sahil kesiminde yer alan illere göre daha düşük bulunmuştur.

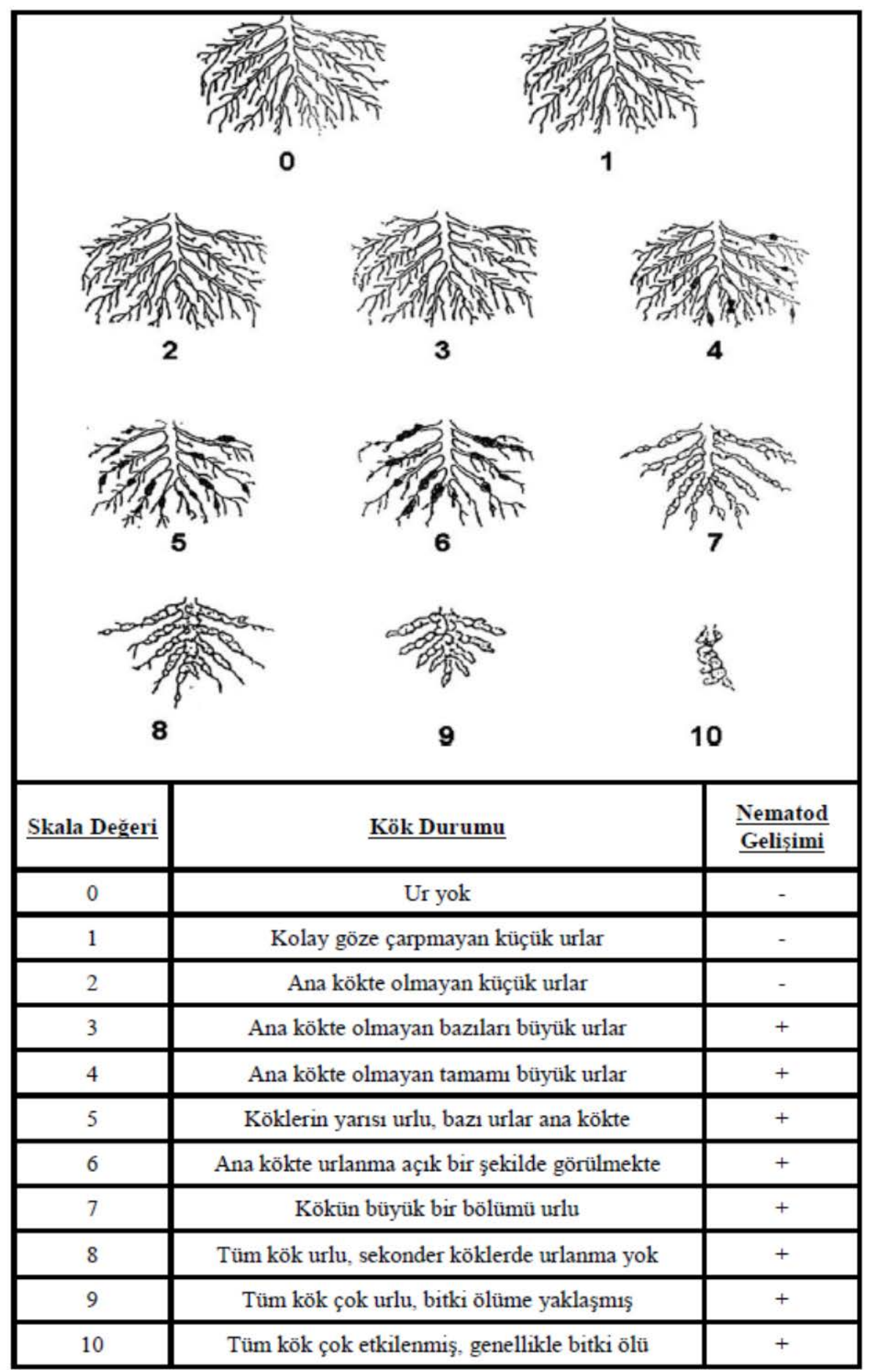

Şekil 1. Köklerin değerlendirildiği ur skalası [17] 


\begin{tabular}{|c|c|c|c|c|c|}
\hline ìl & İlçeler & $\begin{array}{c}\text { Lokasyon } \\
\text { Sayısı }\end{array}$ & $\begin{array}{c}\text { İncelenen Sera } \\
\text { Adedi }\end{array}$ & $\begin{array}{l}\text { Bulassık Sera } \\
\text { Adedi }\end{array}$ & $\begin{array}{l}\text { Bulaşıklık } \\
\text { Oranı (\%) }\end{array}$ \\
\hline \multirow{6}{*}{ Samsun } & Çarşamba & 18 & 91 & 43 & 47,25 \\
\hline & Bafra & 16 & 55 & 23 & 41,82 \\
\hline & Terme & 6 & 39 & 19 & 48,72 \\
\hline & Tekkeköy & 5 & 9 & 4 & 44,44 \\
\hline & Alaçam & 2 & 10 & 6 & 60 \\
\hline & Ondokuzmayıs & 2 & 6 & 3 & 50 \\
\hline \multirow{3}{*}{ Amasya } & TOPLAM & 49 & 210 & 98 & 46,67 \\
\hline & Merkez & 3 & 55 & 16 & 34,88 \\
\hline & Taşova & 1 & 7 & 0 & 0 \\
\hline \multirow{5}{*}{ Tokat } & TOPLAM & 4 & 62 & 16 & 25,81 \\
\hline & Merkez & 2 & 8 & 0 & 0 \\
\hline & Turhal & 2 & 3 & 0 & 0 \\
\hline & Niksar & 2 & 8 & 0 & 0 \\
\hline & Erbaa & 5 & 24 & 13 & 54,17 \\
\hline \multirow{3}{*}{ Sinop } & TOPLAM & 11 & 43 & 13 & 30,23 \\
\hline & Merkez & 5 & 28 & 11 & 39,29 \\
\hline & Gerze & 1 & 1 & 1 & 100 \\
\hline \multirow{3}{*}{ Ordu } & TOPLAM & 6 & 29 & 12 & 41,38 \\
\hline & Merkez & 3 & 11 & 3 & 27,27 \\
\hline & Perşembe & 6 & 19 & 10 & 52,63 \\
\hline \multirow{3}{*}{ Çorum } & TOPLAM & 9 & 30 & 13 & 43,33 \\
\hline & Merkez & 7 & 40 & 12 & 30 \\
\hline & TOPLAM & 7 & 40 & 12 & 30 \\
\hline \multicolumn{2}{|c|}{ GENEL TOPLAM } & 86 & 414 & 164 & 39,61 \\
\hline
\end{tabular}

Samsun'da inceleme yapılan seraların yaklaşık yarısı (91 sera) Çarşamba ilçesinde bulunmaktadır. Çarşamba'da 18 lokasyonda incelenen seraların 43’ü $(\% 47,25)$ bulaşık olarak belirlenmiştir (Tablo 2). Bu ilçedeki lokasyonların 2'si dışında hepsinde kök-ur nematoduna rastlanmıştır. Bafra ilçesinde, 16 lokasyonda survey çalışması gerçekleştirilmiş olup, incelenen 55 seranın 23'ü $(\% 41,82)$ kök-ur nematodu ile bulaşık olup, 6 lokasyonda ise bulaşık sera tespit edilmemiştir. Terme ilçesinde ise 6 lokasyonda incelenen 39 sera'nın 19'unun $(\% 48,72)$ kök-ur nematodu ile bulaşık olduğu belirlenmiştir. Survey yapılan diğer ilçelerden, Tekkeköy'de 9 seradan 4'ü $(\% 44,44)$, Alaçam'da 10 seradan 6'sı (\%60) ve Ondokuzmayıs'ta 6 seradan 3'ü (\%50) kök-ur nematodu ile bulaşıktır.

Orta Karadeniz Bölgesi'nde Samsun'dan sonra sera alanı bakımından 2. sırada bulunan Amasya ilinde, merkeze bağlı 3 lokasyon ile Taşova ilçesinde bulunan 1 lokasyonda survey çalışması yapılmış ve incelenen 62 seranın 16'sının (\%25,81) kök-ur nematodu ile bulaşık olduğu tespit edilmiştir (Tablo 2). Amasya merkezdeki lokasyonlar, birlikte değerlendirildiğinde seraların \%29,09'unun kök-ur nematodu ile bulaşık olduğu belirlenmiştir. Taşova ilçesinde survey çalışmasının yapıldığı Umutlu köyünde ise kökur nematodu ile bulaşık sera saptanmamıştır.

Tokat il merkezi ile Turhal, Niksar ve Erbaa ilçelerindeki 11 lokasyonda incelenen 43 seranın 13’ü $(\% 30,23)$ kök-ur nematodu ile bulaşıktır (Tablo 2). Tokat ilinde yürütülen arazi çalışmasında, kök-ur nematodu ile bulaşıklığa sadece Erbaa ilçesinde rastlanmıştır. Bu ilçedeki lokasyonlardan 2'si dışındaki bütün lokasyonların değişik oranlarda bulaşık olduğu belirlenmiş ve incelenen 23 seradan 13'ünde $(\% 51,17)$ kök-ur nematodu saptanmıştır.

Sinop il merkezi ve Gerze ilçesindeki arazi çalışmalarında, 6 lokasyonda incelenen 29 seradan 12'si (\%41,38) kök-ur nematodu ile bulaşık olarak tespit edilmiştir (Tablo 2). Merkezde bulunan 1 lokasyon dışında, bütün lokasyonlarda kök-ur nematodunun varlığı saptanmıştır. 
Ordu’da kök-ur nematodlarının varlığını tespit edebilmek için yapılan arazi çalışmasında ise il merkezinden 3 lokasyon ile Perşembe ilçesinden 6 lokasyon incelenmeye alınmış ve 30 seradan 13'ünde $(\% 43,33)$ bulaşıklık belirlenmiştir (Tablo 2). İl merkezinde 1 ve Perşembe ilçesinde 1 olmak üzere 2 lokasyon dışında inceleme yapılan bütün lokasyonlarda kök-ur nematodu tespit edilmiştir.

Çorum ilinde 7 lokasyonda yapılan survey çalışmasında incelenen 40 seradan 12'sinin (\%30) kök-ur nematodu ile bulaşık olduğu belirlenmiştir (Tablo 2). Seracılığın yoğun yapıldığı 2 lokasyon dışında, kök-ur nematodu tespit edilmemiştir.

Orta Karadeniz Bölgesi’nde kök-ur nematodları bakımından incelemeye alınan seraların yaklaşık \%60'ında (245 sera) hıyar bitkisi yetiştirildiği ve bunların \%48,16’sının (118 sera) bulaşı olduğu tespit edilmiştir (Tablo 3). Domates yetiştiriciliğinin yapıldığı 132 seranın \%25'inin (33 sera), biber yetiştiriciliğinin yapıldığı 24 seranın ise \%29,17'sinin (7 sera) kök-ur nematodu ile bulaşık olduğu belirlenmiştir. $\mathrm{Bu}$ bitkilerin dışında az sayıda da olsa, özellikle bölgenin sahil kesimindeki illerinde, patlıcan ve kavun bitkisinin yetiştirildiği seraların \%50'sinin, fasulye bitkisinin yetiştirildiği seraların ise \%33,33’ünün kök-ur nematodu ile bulaşık olduğu saptanmıştır.

Bölgedeki yazlık sebze seralarının, yetiştirilen bitkilere göre il ve ilçelerdeki bulaşık oranına bakıldığında, survey yapılan bütün illerde kök-ur nematodu ile bulaşık hıyar serası tespit edilmiştir (Tablo 3). Sinop $(\% 58,82)$ ve Samsun $(\% 53,15)$ illerinde hıyar seralarının yarısından fazlasının kök-ur nematodu ile bulaşık olduğu belirlenmiştir. Diğer illerde ise bu bitkilerin yetiştirildiği seraların bulaşıklık oranının Çorum ve Amasya'da \%40, Tokat'ta \%35, Ordu'da ise \%33,33 olduğu saptanmıştır. Domates bitkisinin yetiştirildiği seraların kök-ur nematodu ile bulaşıklık oranı, Ordu $(\% 54,55)$ dışındaki diğer illerde oldukça düşüktür. Çorum ilindeki domates seralarında ise kök-ur nematodu tespit edilmemiştir. Sinop'taki domates seralarının \%28,57, Samsun’un \%26,09, Tokat'ın \%25 ve Amasya’nın \%20’si kök-ur nematodu ile bulaşıktır. Sadece 3 ilde biber seraları kök-ur nematodu bakımından incelenmeye alınmış olup, bulaşıklık oranı Samsun ilinde \%41,67, Tokat ve Ordu'da \%33,33 olarak saptanmıştır. Yetiştiriciliği az olduğu için daha az inceleme yapılan patlıcan, kavun ve fasulye bir arada değerlendirildiğinde, bu bitkilerin yetiştirildiği seraların \%46,15'de kök-ur nematodu tespit edilmiştir.

Bölgedeki seraların bulaşıklık seviyesini belirlemek amacıyla bitki kökleri 0-10 skalasına göre değerlendirilmiştir. Bu değerlendirmeye göre incelenen bitki köklerinde urlanma olmayan yani kök-ur nematodu ile bulaşıklığın tespit edilmediği sera oranı, Amasya'da \%74,19 (46 sera), Çorum'da \%70 (28 sera), Tokat’ta \%69,77 (30 sera), Sinop’ta \%58,62 (17 sera), Ordu’da \%56,67 (17 sera) ve Samsun’da \%53,33 (112 sera)'dür (Tablo 4). Skala değerlerinden 1 ve 2'ye hiçbir sera alanında rastlanmamıştır. Skala değerinin 3 olduğu sera ise sadece Samsun ilindedir. Kök-ur nematodu ile bulaşık seralarda en fazla görülen ur skala değerleri $7(\% 10,87), 8(\% 8,70)$ ve $9(\% 7,73)$ 'dur. En yüksek skala değeri olan 10 ise Samsun'dan 4, Sinop'tan 1 olmak üzere sadece 5 serada $(\% 1,21)$ tespit edilmiştir. 
Tablo 3. Orta Karadeniz Bölgesi’nde örnekleme yapılan il ve ilcelerdeki seralarda yetistirilen bitkiler ve kök-ur nematodu ile bulasıklık oranları*

\begin{tabular}{|c|c|c|c|c|c|c|c|c|c|c|c|}
\hline \multirow[b]{2}{*}{ İl } & \multirow[b]{2}{*}{ İlçe } & \multicolumn{2}{|c|}{ Hıyar } & \multicolumn{2}{|c|}{ Domates } & \multicolumn{2}{|c|}{ Biber } & \multicolumn{2}{|c|}{ Diğer } & \multicolumn{2}{|c|}{ TOPLAM } \\
\hline & & $\begin{array}{c}\text { Bulaşık } \\
\text { Sera Adedi }\end{array}$ & $\begin{array}{l}\text { Bulaşıklık } \\
\text { Oranı (\%) }\end{array}$ & $\begin{array}{c}\text { Bulaşık } \\
\text { Sera Adedi }\end{array}$ & $\begin{array}{l}\text { Bulaşıklık } \\
\text { Oranı (\%) }\end{array}$ & $\begin{array}{c}\text { Bulaşılk } \\
\text { Sera Adedi }\end{array}$ & $\begin{array}{l}\text { Bulaşıklık } \\
\text { Oranı (\%) }\end{array}$ & $\begin{array}{c}\text { Bulaşık } \\
\text { Sera Adedi }\end{array}$ & $\begin{array}{l}\text { Bulaşıklık } \\
\text { Oranı (\%) }\end{array}$ & $\begin{array}{c}\text { Bulaşık } \\
\text { Sera Adedi }\end{array}$ & $\begin{array}{l}\text { Bulaşıklık } \\
\text { Oranı (\%) }\end{array}$ \\
\hline \multirow{6}{*}{ Samsun } & Çarşamba & $\begin{array}{l}\text { Sera Adedi } \\
33\end{array}$ & $\begin{array}{l}\text { Orani (\%) } \\
55,93\end{array}$ & $\begin{array}{c}\text { Sera Adedi } \\
4\end{array}$ & $\begin{array}{c}\text { Oranı (\%) } \\
18\end{array}$ & $\begin{array}{c}\text { Sera Adedi } \\
4\end{array}$ & $\begin{array}{c}\text { Orani (\%) } \\
50\end{array}$ & $\begin{array}{l}\text { Sera Adedi } \\
\qquad 2^{1,2}\end{array}$ & $\begin{array}{c}\text { Orani (\%) } \\
100\end{array}$ & $\begin{array}{c}\text { Sera Adedi } \\
43\end{array}$ & $\begin{array}{c}\text { Orani (\%) } \\
47,25\end{array}$ \\
\hline & Bafra & 20 & 42,55 & 2 & 40 & - & - & $1^{1}$ & 33,33 & 23 & 41,82 \\
\hline & Terme & 15 & 55,56 & 3 & 42,86 & 1 & 33,33 & 0 & 0 & 19 & 48,72 \\
\hline & Tekkeköy & 1 & 100 & 2 & 28,57 & - & - & $1^{1}$ & 100 & 4 & 44,44 \\
\hline & Alaçam & 5 & 100 & 1 & 25 & 0 & 0 & - & - & 6 & 60 \\
\hline & Ondokuzmayıs & 2 & 50 & 0 & 0 & - & - & $1^{1}$ & 100 & 3 & 50 \\
\hline \multicolumn{2}{|c|}{ TOPLAM } & 76 & 53,15 & 12 & 26,09 & 5 & 41,67 & 5 & 55,56 & 98 & 46,67 \\
\hline \multirow{4}{*}{ Amasya } & Merkez & 8 & 44,44 & 8 & 21,62 & - & - & - & - & 16 & 29,09 \\
\hline & Taşova & 0 & 0 & 0 & 0 & 0 & 0 & - & - & 0 & 0 \\
\hline & & 8 & 40 & 8 & 20 & $\mathbf{0}$ & $\mathbf{0}$ & - & - & 16 & 25,81 \\
\hline & Merkez & 0 & 0 & 0 & 0 & 0 & 0 & - & - & 0 & 0 \\
\hline \multirow{3}{*}{ Tokat } & Turhal & 0 & 0 & 0 & 0 & - & - & - & - & 0 & 0 \\
\hline & Niksar & 0 & 0 & 0 & 0 & - & - & - & - & 0 & 0 \\
\hline & Erbaa & 7 & 70 & 5 & 41,67 & 1 & 50 & - & - & 13 & 54,17 \\
\hline \multicolumn{2}{|c|}{ TOPLAM } & 7 & 35 & 5 & 25 & 1 & 33,33 & - & - & 13 & 30,23 \\
\hline \multirow{3}{*}{ Sinop } & Merkez & 9 & 56,25 & 2 & 28,57 & 0 & 0 & 0 & 0 & 11 & 39,29 \\
\hline & Gerze & 1 & 100 & - & - & - & - & - & - & 1 & 100 \\
\hline & & 10 & 58,82 & 2 & 28,57 & $\mathbf{0}$ & $\mathbf{0}$ & $\mathbf{0}$ & $\mathbf{0}$ & 12 & 41,38 \\
\hline \multirow{3}{*}{ Ordu } & Merkez & 0 & 0 & 3 & 60 & - & - & - & - & 3 & 27,27 \\
\hline & Perşembe & 5 & 55,56 & 3 & 50 & 1 & 33,33 & $1^{3}$ & 100 & 10 & 52,63 \\
\hline \multirow{2}{*}{\multicolumn{2}{|c|}{ TOPLAM }} & 5 & 33,33 & 6 & 54,55 & 1 & 33,33 & 1 & 100 & 13 & 43,3 \\
\hline & & 12 & 40 & 0 & 0 & 0 & 0 & - & - & 12 & 30 \\
\hline \multicolumn{2}{|c|}{ TOPLAM } & 12 & 40 & $\mathbf{0}$ & $\mathbf{0}$ & $\mathbf{0}$ & $\mathbf{0}$ & - & - & 12 & 30 \\
\hline \multicolumn{2}{|c|}{ GENEL TOPLAM } & 118 & 48,16 & 33 & 25 & 7 & 29,17 & 6 & 46,15 & 164 & 39,61 \\
\hline
\end{tabular}


Tablo 4. Orta Karadeniz Bölgesi’ndeki örnekleme yapılan illerdeki incelenen seralarda tespit edilen ur skalası değerlerinin görülme

\begin{tabular}{cccccccc}
\hline Skala Değerleri & Samsun & Amasya & Tokat & Sinop & Ordu & Çorum & TOPLAM \\
Skala 0 & 53,33 & 74,19 & 69,77 & 58,62 & 56,67 & 70 & 60,39 \\
Skala 1 & 0 & 0 & 0 & 0 & 0 & 0 & 0 \\
Skala 2 & 0 & 0 & 0 & 0 & 0 & 0 & 0 \\
Skala 3 & 1,43 & 0 & 0 & 0 & 0 & 0 & 0,72 \\
Skala 4 & 5,24 & 1,61 & 9,30 & 0 & 6,67 & 2,5 & 4,59 \\
Skala 5 & 0,95 & 1,61 & 2,33 & 0 & 0 & 0 & 0,97 \\
Skala 6 & 3,81 & 9,68 & 6,98 & 3,45 & 3,33 & 2,5 & 4,83 \\
Skala 7 & 13,81 & 1,61 & 2,33 & 17,24 & 20 & 7,5 & 10,87 \\
Skala 8 & 11,90 & 1,61 & 2,33 & 6,90 & 13,33 & 7,5 & 8,70 \\
Skala 9 & 7,62 & 9,68 & 6,98 & 10,34 & 0 & 10 & 7,73 \\
Skala 10 & 1,90 & 0 & 0 & 3,45 & 0 & 0 & 1,21 \\
TOPLAM & 100 & 100 & 100 & 100 & 100 & 100 & 100 \\
\hline
\end{tabular}

\section{Tartıșma ve Sonuc}

$\mathrm{Bu}$ çalışma ile Amasya, Sinop, Ordu ve Çorum illeri için kök-ur nematodu bulaşıklık durumu ilk kez belirlenmiştir. Samsun ilinde ise daha önce kapsamlı bir çalışma sadece Bafra ve Çarşamba ilçelerinde yürütülmüştür [14 ve 15]. Tokat ilinde ise Merkez, Erbaa, Niksar, Pazar ve Turhal ilçeleri açık alan ve seralarındaki sebze üretim alanlarında kök-ur nematodlarının bulaşıklık durumu birlikte değerlendirilmiştir [16].

Samsun ili, Çarşamba ilçesinde incelenen 91 seranın 43’ü $(\% 47,25)$, Bafra ilçesinde ise 55 seradan 23’ü $(\% 41,82)$ kök-ur nematodları ile bulaşıktır. Çarşamba ilçesindeki kök-ur nematodu ile bulaşıklık oranının Bafra'dan yüksek olduğu daha önce yapılan çalışmalarda da ortaya konulmuştur [14 ve 15]. Çarşamba ve Bafra'daki seralar için ortaya konulan bulaşıklık oranları, aynı bölgedeki seralarda daha önce yapılan çalışmaya göre biraz daha düşüktür [15]. Bunun nedeni, daha önce survey yapılan lokasyonlara ilave olarak seracılığın yoğun yapılmadığı ve bulaşıklık oranlarının düşük olduğu farklı sera alanlarının da çalışmaya dahil edilmiş olmasıdır. Ayrıca, daha önceki yıllarda yapılan çalışmada, üreticilerin kök-ur nematodları hakkında bilgi sahibi olmadıkları bilinmektedir. Bu survey çalışması sırasında ise üreticilerin kök-ur nematodları hakkındaki bilgilerinin arttığı ve nematod zararından korunmak için gerekli önlemleri aldıkları görülmektedir. Özellikle son yıllarda serada domates yetiştiricilerinin büyük bir bölümü nematoda dayanıklı çeşit ve anaçları kullanmaktadır. Daha önceki çalışmada, her iki ilçede en fazla zararın domates bitkisinde görüldüğü ortaya konmuştu [14]. Domatesteki bu zarar oranının nedeni olarak da yetiştirilen domates çeşitlerinin pek çoğunun hassas olması gösterilmiştir. Bu çalışmada ise kök-ur nematodu ile bulaşıklığın en fazla görüldüğü alanların hıyar yetiştiriciliğinin yapıldığı seralar olduğu ve benzer sonuçların Katı ve Mennan [15] tarafindan da ortaya konulduğu tespit edilmiştir. Özellikle 2000'li yıllardan sonra dayanıklı domates çeşitlerinin kullanımının artmaya başlaması ve son yıllarda dayanıklı anaçlardan oluşan aşılı çeşitlerin yaygınlaşması, domates yetiştirilen alanlarda kök-ur nematodu ile bulaşıklığın azalmasına katkı sağladığı düşünülmektedir.

Tokat ilinde kök-ur nematodlarının yayılış ve bulaşık durumu değerlendirildiğinde, sadece Erbaa ilçesindeki seralarda kök-ur nematoduyla bulaşıklık $(\% 54,17)$ tespit edilmiştir. Bu bölgede daha önce yapılan çalışmada da benzer sonuçlar elde edilmiştir [16]. Sera alanı olarak Niksar ve Erbaa'da çalışma yapan araştırıcılar, Erbaa'da incelenen 50 seranın \%34,5'inin kök-ur nematodu ile bulaşık olduğunu 
bildirmişlerdir. Niksar'da ise sadece 3 seranın $(\% 5,5)$ bulaşık olduğu belirtilmiştir. İl merkezi ile Turhal ilçesindeki sebze yetiştirilen açık alanlarda da inceleme yapan araştırıcılar, bu çalışmada olduğu gibi kökur nematodu ile bulaşık bitkilere rastlamamışlardır.

Çalışma sonucunda, Orta Karadeniz Bölgesi'nin iç kesimlerinde yer alan illerin kök-ur nematodu ile bulaşıklık oranlarının, sahil kesiminde yer alanlara göre daha düşük olduğu belirlenmiştir.

\section{Teşekkür}

Arazi çalışmaları sırasında yapmış oldukları yardımlardan dolayı Gıda Tarım ve Hayvancılık Müdürlüğ̈̈’nde görevli Ziraat Mühendisleri Ali Rıza SOLAK, Evrim EKERCAN, Ayșe YİĞíT, Çetin ŞAHIN, Kadir YILDIZ, Birol BEYTUT, Mustafa KARA, Cemil ÇELIK, Kaan ALTAŞ ve Nuray ÇELIK'e, Ordu Üniversitesi Bitki Koruma Bölümü’nden Yrd. Doç. Dr. Faruk AKYAZI ve Arş. Gör. Anıl Firat FELEK'e ve Ondokuz Mayıs Üniversitesi Bitki Koruma Bölümü yüksek lisans öğrencileri Murat GÜNGÖR ve Oğuzcan OCAKLI'ya teşekkür ederiz.

\section{Kaynaklar}

[1] Sevgican A., Tüzel Y., Gül A., Eltez R. Z., “Türkiye'de örtüaltı yetiştiriciliği” V. Türkiye Ziraat Mühendisliği Teknik Kongresi, 17-21 Ocak, 679-707, Ankara, 2000

[2] Tüzel Y., Gül, A., Daşgan, H. Y., Özgür, M., Özçelik, N., Boyacı, H. F., Ersoy, A., “Örtüaltı yetiştiriciliğinde gelişmeler” VI. Türkiye Ziraat Mühendisliği Teknik Kongresi, 3-7 Ocak, 609627, Ankara, 2005

[3] Türkiye İstatistik Kurumu "http://tuikapp.tuik.gov.tr/bitkiselapp/bitkisel.zul” (Ziyaret tarihi: 24 Ekim 2013)

[4] Mitkowski N. A., Abawi G. S., "Root-knot nematodes" The Plant Health Instructor, DOI:10.1094/PHI-I-2003-0917-01, 2003

[5] Greco N., Di Vito M., 2009. "Population dynamics and damage levels”, Edited by Pery R. N., Moens M., Starr J. L., CAB International, UK, 246-274, 2009

[6] Collange B., Navarrete M., Peyre G., Mateille T., Tchamitchian M., " Root-knot nematode (Meloidogyne) management in vegetable crop production: The challenge of an agronomic system analysis” Crop Protection, 30, 1251-1262, 2011

[7] Stirling G. R., "Biological control of plant parasitic nematodes: progress, problems and prospects”, CAB International, 282s., Wallingford, UK, 1991

[8] Siddiqi M. R., "Tylenchida parasites of plants and insects" CAB International, 864s., Wallingford, UK, 2000

[9] Sikora R. A., Fernandez E., “ Nematode parasites on vegetables” Edited by Luc M., Sikora R. A., Bridge J., CAB International, UK, 319-392, 2005

[10] Gediz A., "Türkiye Şekerpancarı sahalarında kök solucanı (Heterodera marioni Cornu)", Türkiye Şeker Fabrikaları A.Ş. Neş., No 21, Ankara, 1952

[11] Alkan B., “Türkiye'nin zararlı nematod (Nematoda) fauna's1 üzerinde ilk incelemeler” Bitki Koruma Bülteni, 2 (12), 17-25, 1962 
[12] Yüksel H., "Karadeniz Bölgesinde tesadüf edilen Meloidogyne incognita varyasyonu hakkında” Bitki Koruma Bülteni, 6 (1), 35-38, 1966

[13] Bora A., "Karadeniz Bölgesi bitki parazit nematodlarının tür ve yayılış alanlarının tesbiti ve ilaçlı mücadele imkanları üzerinde araştırmalar” Bitki Koruma Bülteni, 10 (1), 53-71, 1970

[14] Mennan S., Ecevit O., "Bafra ve Çarşamba Ovaları yazlık sebze ekim alanlarındaki kök ur nematodları (Meloidogyne spp.)'nın biyolojisi, yayılışı ve bulaşık oranları üzerine araştırmalar” Türkiye III. Entomoloji Kongresi, 24-28 Eylül, 700-705, Ankara, 1996

[15] Kat1 T., Mennan S., "Researches on species and race determination of root-knot nematodes (Meloidogyne spp.) found in greenhouse of Samsun, Turkey” XXVIII International Symposium of the European Society of Nematologists, 5-9 June, Abstract Book, 130 s, Blogoevgrad, Bulgaria, 2006

[16] Akyazı F., Ecevit O., “Tokat ili sebze alanlarındaki kök-ur nematod (Meloidogyne spp.)’larının Yayılışları ve Tür Tespiti” Anadolu Tarım Bilimleri Dergisi, 26 (1), 1-9, 2011

[17] Piedra-Buena A., López-Pérez J. A., Díez-Rojo M. A., Robertson L., Castro-Lizazo I., Bello A. "Screening of three sweet potato (Ipomoea batatas L.) cultivars for resistance to different virulence groups of root-knot nematodes (Meloidogyne spp.) under controlled conditions” Crop Protection, 30, 134-140, 2011 